\title{
Monogenea of Chinese marine fishes. XVIII. Two monocotylids, including a new species, from the blotched fantail ray Taeniurops meyeni (Elasmobranchii: Dasyatidae) in the South China Sea
}

\author{
Shanmei Cao, Xuejuan Ding, Jianying Zhang and Lin Liu
}

Key Laboratory of Ecology and Environmental Science in Guang Dong Higher Education, College of Life Science, South China Normal University, Guangzhou, 510631, China

\begin{abstract}
Two monogenean species are recorded from a blotched fantail ray, Taeniurops meyeni (Müller et Henle) (Dasyatidae), kept in a public aquarium at the Guangzhou Ocean World. Heterocotyle taeniuropi sp. n. was obtained from the gills. It is similar to Heterocotyle similis Neifar, Euzet et Ben Hassine, 1998 and H. scotti Neifar, Euzet et Ben Hassine, 1998, both of which have a similar male copulatory organ, but it can be distinguished from these two species by aspects of the morphology of the male copulatory organ, which is tubular, straight or slightly curved with a sclerotized accessory piece and an asymmetrical funnel-shaped opening at the proximal end, and recurved at the distal end. Dendromonocotyle pipinna Chisholm et Whittington, 2002, which is a new record for Chinese waters, was collected from the body surface of the same host. Its main features are almost the same as in the original description, except that it exhibits a variable number of marginal papillae.
\end{abstract}

Keywords: Monogenea, Heterocotyle taeniuropi, Dendromonocotyle pipinna, Taeniurops meyeni, South China Sea

Whittington and Chisholm (2003) reported that about 200 valid monogenean species have been recorded from chondrichthyans of seven families. Over the next few years another 25 species have been added (Zoological Record 2004-2007). In Chinese waters, 19 species have been collected from chondrichthyans, 9 of them parasitizing dasyatid hosts; these are: Monocotyle kuhlii Young, 1967, M. undosocirrus Timofeeva, 1984, Heterocotyle chinensis Timofeeva, 1983, H. confusa Timofeeva, 1983, H. armata Timofeeva, 1983, Decacotyle youngi (Timofeeva, 1983), Dasybatotrema spinosum Timofeeva, 1983, D. rajae Timofeeva, 1983 and Erpocotyle sp. II of Zhang, 2001 (Zhang et al. 2003). In this paper, two species from Taeniurops meyeni (also known as Taeniura meyeni) are reported.

\section{MATERIALS AND METHODS}

A blotched fantail ray, Taeniurops meyeni (Müller et Henle) which was originally caught in the South China Sea near Hainan Island, transported to the Guangzhou Ocean World on 16th September, 1999 and then kept on display in the aquarium, died and was examined for ectoparasites on 28th January, 2000. Each gill arch was excised, placed in filtered sea water (FSW) and examined under a stereo-microscope using incident light. The body surface was also carefully checked. The gills and the dorsal body surface were found to be parasitized by monogeneans. Worms were removed from the gill lamellae using fine needles and transferred to dishes containing clean FSW. Those on the skin were removed directly by dipping the fish in fresh water. The parasites were treated following the method of Zhang et al. (1997) for further observation.

Drawings were made with the aid of a drawing tube. Measurements, made using a calibrated eyepiece, are given in micrometres as the mean followed in parentheses by the range and the number of measurements (n).

\section{RESULTS}

Heterocotyle taeniuropi sp. n.

Fig. 1

Description (measurements based on 39 flattened mounted specimens): Body length, including haptor, 766 (510-1030, $\mathrm{n}=37)$; maximum width 282 (140-370, $\mathrm{n}=37$ ) at level of ovary (Fig. 1A). Haptor circular; maximum diameter $242(140-370, n=37)$. Four semicircular bumps located dorsal to both posterior and posterolateral pairs of haptoral loculi; margin of bumps sclerotized (Fig. 1A). Ventral haptor divided into 1 central and 8 peripheral loculi separated by marginal septa. Margins of loculi with sinuous sclerotized ridges; ridges single on posteromedian and posterolateral septa, double on lateral septa and triple on anterolateral and anterior septa, i.e. resulting in 1-1-2-3-3 configuration of Neifar et al. (1998). Sinuous sclerotized ridges also present on both inner and outer ring septa (Fig. 1B). Hamuli 60 (48-95, n=36) long, located on marginal membrane next to posterolater- 


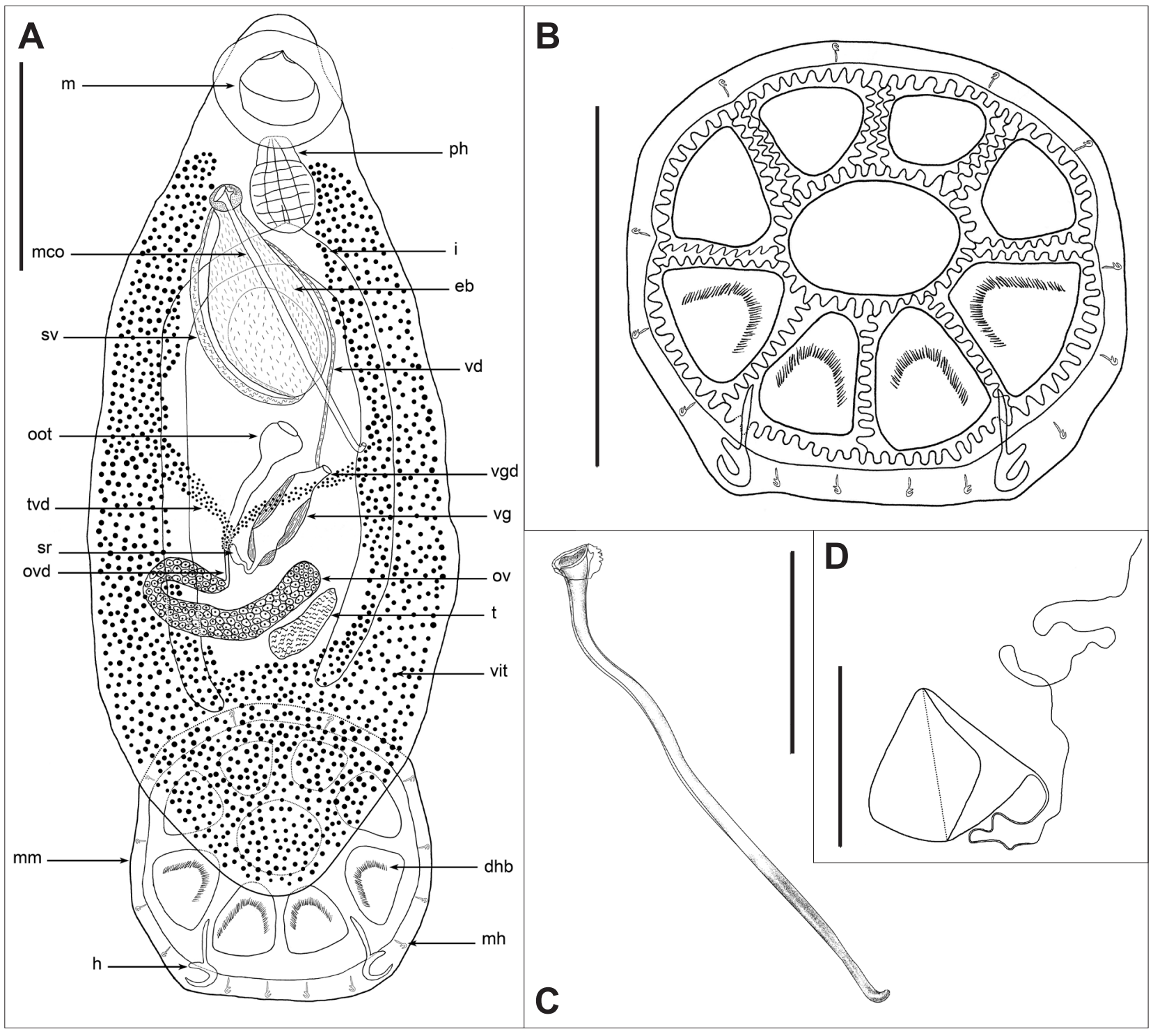

Fig. 1. Heterocotyle taeniuropi sp. n. from Taeniurops meyeni from the South China Sea. A - whole worm (dorsal view); B - haptor (ventral view); C - male copulatory organ; D - egg. Abbreviations: dhb - dorsal haptoral bump; eb - ejaculatory bulb; $\mathrm{h}$ - hamulus; $\mathrm{i}$ - intestinal caecum; $\mathrm{m}$ - mouth; mco - male copulatory organ; $\mathrm{mh}$ - marginal hook; $\mathrm{mm}$ - marginal membrane; oot - ootype; ov - ovary; ovd - oviduct; $\mathrm{ph}$ - pharynx; sr - seminal receptacle; sv - seminal vesicle; $\mathrm{t}$ - testis; tvd - transverse vitelline duct; vd - vas deferens; vg - vagina; vgd - vaginal duct; vit - vitellarium. Scale bars: A, B = $200 \mu \mathrm{m} ; \mathrm{C}, \mathrm{D}=100 \mu \mathrm{m}$.

al septa; longer outer roots extend into septa, 37 (28-73, $\mathrm{n}=36)$ long, noticeably distant from inner root, $11(5-18$, $\mathrm{n}=37$ ) long. Fourteen marginal hooks distributed in marginal membrane as illustrated (Fig. 1A, B).

Mouth muscular, circular or oval, $74(50-105, \mathrm{n}=37)$ $\times 63(35-103, \mathrm{n}=37)$. Pharynx muscular, $73(45-95$, $\mathrm{n}=37)$ long, 59 (43-88, $\mathrm{n}=37$ ) wide, comprising short oral region connected to mouth and longer posterior region. Head organs and glands not observed. Intestinal caeca unbranched laterally, run parallel with body margin, ending blindly posterior to testis.

Testis single, irregular, lateral to the ovary, intercaecal, $155(50-265, \mathrm{n}=27) \times 105(50-188, \mathrm{n}=27)$. Vas deferens not traced from testis, but observed on left side ventral to vaginal duct, extending to level of ejaculatory bulb, then crossing ventrally to right side of ejaculatory bulb; curving posteriorly and expanding slightly to form seminal vesicle which opens into posterior region of ejaculatory bulb. Ejaculatory bulb oval, with deeply staining central region, $176(100-270, \mathrm{n}=34)$ long, maximum width $106(58-175, \mathrm{n}=34)$. Male copulatory organ tubular, straight or slightly curved and slender, 271 $(193-330, \mathrm{n}=37)$ long, $7(5-8, \mathrm{n}=37)$ in diameter, with an asymmetrical funnel-shaped opening at proximal end, $23(15-30, \mathrm{n}=37)$ in size, and distal end narrowed and recurved upward; sclerotized accessory piece with jagged 
edge present on the proximal end of male copulatory organ (Fig. 1C).

Ovary elongate, loops dorsoventrally around right intestinal caecum, then narrows and gives rise to oviduct. Oviduct receives duct from seminal receptacle and common vitelline duct, finally entering ootype. Ootype rhomboid, 62 (37-95, $\mathrm{n}=24)$ long, 68 (47-115, $\mathrm{n}=24)$ wide, median, posterior to ejaculatory bulb, directed anteriorly and opening at common genital pore. Vaginal opening ventral on left side; vagina $93(50-150, \mathrm{n}=15) \times 47(28-$ $78, \mathrm{n}=15$ ), weakly muscular, lacking sclerotisation and spines, connected to seminal receptacle. No spermatophore observed in vagina. Vitellarium extends from level of anterior region of pharynx to posterior margin of body proper; transverse vitelline ducts unite medially; common vitelline duct runs posteriorly, dorsal to ootype and joins oviduct. Eggs, inside the worm, tetrahedral, side length 62 (46-86, $\mathrm{n}=12)$, with single polar filament 492 (356-563, $\mathrm{n}=6$ ) long, present on one corner (Fig. 1D).

Type host: Taeniurops meyeni (Müller et Henle), the blotched fantail ray (Elasmobranchii: Dasyatidae).

Infection site: Gills.

Type locality: Probably South China Sea near Hainan Island; fish died in aquarium at Guangzhou Ocean World, Guangdong.

Deposition of type material: Holotype(1999091601 ) and 30 paratypes (19990916-02 to -34) in the Fish Parasite Laboratory, College of Life Science, South China Normal University, Guangzhou; 4 paratypes in the Natural History Museum, London (Reg. No. 2007.8.29.4); 4 paratypes in Institute of Parasitology, Academy of Sciences of the Czech Republic, České Budějovice, Czech Republic (No. M-504)

Etymology: The specific name is derived from the generic name of the host.

Remarks. Heterocotyle Scott, 1904 was proposed for monogeneans bearing a haptor with one central and eight peripheral loculi. The type species, $H$. pastinacae Scott, 1904, was collected from the Dornoch Firth in the North Sea. Chisholm (1995) redescribed $H$. pastinacae from specimens collected from the North Sea off Thornham, Norfolk, England, and because type specimens were unavailable, designated a neotype.

Sixteen species of Heterocotyle have been reported, including $H$. americana Hargis, 1955, H. armata Timofeeva, 1983, H. capapei Neifar, Euzet et Ben Hassine, 2000, H. capricornensis Chisholm et Whittington, 1996, $H$. chinensis Timofeeva, 1983, H. confusa Timofeeva, 1983, H. dasyatis Yamaguti, 1965, H. forcifera Neifar, Euzet et Ben Hassine, 1999, H. granulatae Young, 1967, H. minima Scott, 1904, H. mokhtarae Neifar, Euzet et Ben Hassine, 1999, H. pastinacae Scott, 1904, H. pseudominima Hargis, 1955, H. scotti Neifar, Euzet et Ben Hassine, 1998, H. similis Neifar, Euzet et Ben Hassine, 1998, and H. striata Neifar, Euzet et Ben Hassine, 1999. They are
Table 1. Comparison of measurements (in micrometres) of Heterocotyle taeniuropi sp. n., H. similis and H. scotti.

\begin{tabular}{|c|c|c|c|}
\hline & $\begin{array}{l}\text { H. taeniuropi } \\
(\mathrm{n}=39)\end{array}$ & $\begin{array}{l}\text { H. similis }{ }^{1} \\
(\mathrm{n}=25)\end{array}$ & $\begin{array}{l}\text { H. scotti } \\
(\mathrm{n}=25)\end{array}$ \\
\hline Total length & $766(510-1030)$ & $755(650-930)$ & $600(360-890)$ \\
\hline Body width & $282(140-370)$ & $288(220-335)$ & $228(145-350)$ \\
\hline Haptor diameter & $242(140-370)$ & $300(270-350)$ & $214(145-282)$ \\
\hline Hamulus length & $60(48-95)$ & $53(48-55)$ & $46.5(41-52)$ \\
\hline \multicolumn{4}{|l|}{ Pharynx } \\
\hline length & $73(45-95)$ & $112(90-150)$ & $72(52-95)$ \\
\hline width & $59(43-88)$ & $73(50-96)$ & $49(39-65)$ \\
\hline \multicolumn{4}{|l|}{ Vagina } \\
\hline length & $93(50-150)$ & $103(82-170)$ & $60-110$ \\
\hline width & $47(28-78)$ & $40(20-75)$ & $30-58$ \\
\hline \multicolumn{4}{|l|}{ Egg } \\
\hline side length & $62(48-86)$ & $58(55-60)$ & $47(40-55)$ \\
\hline \multicolumn{4}{|l|}{ Ejaculatory bulb } \\
\hline length & $176(100-270)$ & $86(65-115)$ & $94(80-122)$ \\
\hline width & $106(58-175)$ & $53(42-62)$ & $55(38-80)$ \\
\hline \multicolumn{4}{|l|}{$\begin{array}{l}\text { Male copulatory } \\
\text { organ }\end{array}$} \\
\hline length & $271(193-330)$ & $94(85-105)$ & $137(115-155)$ \\
\hline width & $7(5-8)$ & $4.5(4-5)$ & 4 \\
\hline
\end{tabular}

${ }^{1}$ Data taken from Neifar et al. (1998).

distinguished from each other mainly by the morphology of the male copulatory organ.

Heterocotyle taeniuropi is similar to $H$. similis and $H$. scotti in that they all have a similar male copulatory organ and have a similar body size. However, the shape and the length of the male copulatory organ are different in these three species. A comparison of their measurements is presented in Table 1 . The male copulatory organ of $H$. taeniuropi is tubular and straight or slightly curved, and it has the greatest length and widest diameter (Table 1), its proximal opening is an asymmetrical funnel and its distal end is narrowed and recurved, and it bears a sclerotized accessory piece with a jagged edge on its proximal end. Whereas, the male copulatory organ of $H$. similis is the shortest and has a smaller diameter, its proximal opening expands and has an asymmetrical trumpet shape and its distal end is enlarged and recurved. The male copulatory organ of $H$. scotti is also shorter and has a smaller diameter, its proximal end has an asymmetrical trumpet shape, and its distal end is slightly enlarged but uncurved. An accessory piece has not been reported for the latter two species. In addition, the ejaculatory bulb of $H$. taeniuropi is larger than in the other two species. There are also some differences in the configurations of the sinuous sclerotized ridges: those of $H$. taeniuropi and $H$. similis are 1-1-2-3-3, but that of $H$. scotti is 1-1-2-2-3. Moreover, $H$. similis and $H$. scotti were collected from Dasyatis pastinaca Linnaeus, whereas $H$. taeniuropi is from Taeniurops meyeni. Based on the above arguments, we consider $H$. taeniuropi to be a new species and name it after its host. 


\section{Dendromonocotyle pipinna}

Chisholm et Whittington, 2004

H o s t: Taeniurops meyeni (Müller et Henle), the blotched fantail ray (Elasmobranchii: Dasyatidae).

Site of infection: Dorsal body surface.

L o c a 1 i t y: Probably South China Sea near Hainan Island; fish died in aquarium at Guangzhou Ocean World, Guangdong.

Voucher material: 91 specimens are deposited in the Fish Parasite Laboratory, College of Life Science, South China Normal University, Guangzhou, 2 specimens in the Natural History Museum, London (Reg. No. 2007.8.29.2) and 3 specimens in Institute of Parasitology, Academy of Sciences of the Czech Republic, České Budějovice, Czech Republic (No. M-502).

Remarks. Dendromonocotyle pipinna Chisholm et Whittington, 2004 was originally collected from Taeniurops meyeni off Mooloolaba, Queensland, Australia. The present work is a new record for Chinese waters.

Seventeen species are included in Dendromonocotyle Hargis, 1955. Most species of Dendromonocotyle are strictly host-specific, except for D. octodiscus, which has been reported from four host species (Chisholm et al. 2004). The present report of D. pipinna is from the dorsal body surface of T. meyeni, which is the same site as in the original description. Species of this genus are distinguished from each other primarily by the morphology of the male copulatory organ, the presence or absence of hamuli and the morphology of the terminal sclerite on the marginal papillae. According to Chisholm and Whittington (2004), the number of marginal papillae is useful for species identification as different numbers of marginal papillae have been reported on different species of the genus: $D$. lasti Chisholm et Whittington, 2005 has 38 marginal papillae, D. taeniurae Euzet et Maillard, 1967 has 42 and D. akajeii Ho et Perkins, 1980 has 62. Dendromonocotyle pipinna from the South China Sea is morphologically similar to D. pipinna from off Queensland. However, the number of marginal papillae is a little different as D. pipinna was originally reported to have 56 marginal papillae on the haptoral rim, but in 33 specimens of $D$. pipinna from the South China Sea in which marginal papillae could be clearly counted, the numbers recorded were 52 (4 specimens), 53 (2), 54 (4), 55 (7), 56 (10) and 57 (6); the number range of marginal papillae varied between 7 and 8 in the posterior loculus, 6 and 7 (seldom 8) in the posterolateral loculus, and 6 and 7 in the anterolateral loculus and the anterior loculus. We suggest that the number of marginal papillae may be variable in D. pipinna and that this represents an intraspecific variation. Dendromonocotyle ardea Chisholm et Whittington, 1995 was also shown to have a minor variation in the arrangement of marginal papillae, which means that the number and arrangement of marginal papillae in Dendromonocotyle can be variable intraspecifically.

Acknowledgements. This study was supported by the National Natural Science Fund of China (No. 30570222) to Xuejuan Ding and the Natural Science Fund of Guangdong Province (No. 8451063101000345) to Lin Liu. We would like to thank Prof. Dingjie Xing of Guangzhou Ocean World for his great help with fish information and Dr. David I. Gibson of the Natural History Museum, London for his great help with literature and comments on the manuscript.

\section{REFERENCES}

Chisholm L.A. 1995: A redescription of Heterocotyle pastinacae Scott, 1904 (Monogenea: Monocotylidae) from Dasyatis pastinaca (Dasyatididae), with a neotype designation. Syst. Parasitol. 30: 207-211.

Chisholm L.A., Whittington I.D. 2004: Two new species of Dendromonocotyle Hargis, 1955 (Monogenea: Monocotylidae) from the skin of Taeniura meyeni (Dasyatidae) and Aetobatus narinari (Myliobatidae) from aquaria in Queensland, Australia. Syst. Parasitol. 57: 221-228.

Chisholm L.A., Whittington I.D., Fischer A.B.P 2004: A review of Dendromonocotyle (Monogenea: Monocotylidae) from the skin of stingrays and their control in public aquaria. Folia Parasitol. 51: 123-130.

Neifar L., Euzet L., Ben Hassine O.K. 1998: Nouveaux Monocotylidae (Monogenea), parasites branchiaux de Dasyatis pastinaca (L.) (Euselachii, Dasyatidae). Compléments à la descrip-

tion de Heterocotyle pastinacae Scott, 1904. Syst. Parasitol. 41: 197-208.

Scotт T. 1904: On some parasites of fishes new to the Scottish marine fauna. Twenty-second Annual Report of the Fishery Board for Scotland (1903), Part 3: 275-280.

Whittington I.D., Chisholm L.A. 2003: Diversity of Monogenea from Chondrichthyes: do monogeneans fear sharks? In: C. Combes and J. Jourdane (Eds.), Taxonomie, Écologie et Évolution des Métazoaires Parasites. (Livre hommage à Louis Euzet). Tome 2. Presses Universitaires de Perpignan, Perpignan, pp. 339-363.

Zhang J.Y., Liu L., Ding X.J. 1997: Monogenea of Chinese marine fishes. VII. A new species and two new records of the Tetraonchoididae from fishes of the South China and East China Seas. Syst. Parasitol. 38: 197-201.

Zhang J.Y., Yang T.B., Liu L., Ding X.J. 2003: A list of monogeneans from Chinese marine fishes. Syst. Parasitol. 54: 111-130.

Accepted 19 March 2010 